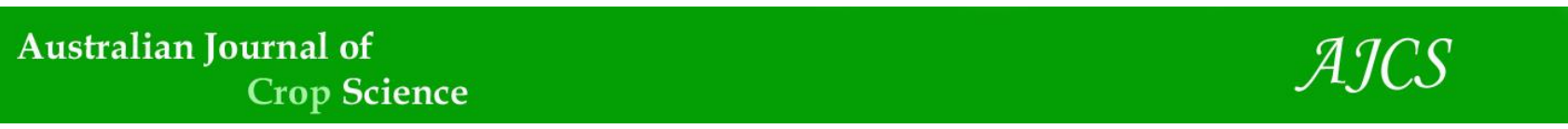

AJCS 14(05):782-787 (2020)

ISSN:1835-2707

doi: 10.21475/ajcs.20.14.05.p2180

\title{
Coating phosphorus fertilizer with renewable natural polymers
}

\author{
Vinícius José Ribeiro ${ }^{1 *}$, Edson Marcio Mattiello ${ }^{1}$, Deusanilde de Jesus Silva², Leonardus Vergütz ${ }^{1}$ \\ ${ }^{1}$ Department of Soil Science, Universidade Federal de Viçosa, Viçosa, MG, Brazil, 36570-900 \\ ${ }^{2}$ Department of Chemical Engineering, Universidade Federal de Viçosa, Viçosa, MG, Brazil, 36570-900
}

*Corresponding author: vj.ribeiro@yahoo.com.br

Abstract

\begin{abstract}
Low phosphorus use efficiency (PUE) is one of the major reasons of poor production worldwide. Among the various approaches used to enhance PUE, polymer coated fertilizers are relatively a new concept. Its main advantages are that they dissolve slowly and release nutrients to plants gradually during the growing season. Keeping this in view, a study was performed in the laboratory to evaluate polymers coated monoammonium phosphate (MAP) to enhance PUE. Commercial MAP and MAP coated with biodegradable polymers with Krafit black liquor (BL) and cellulose acetate (CA) in the concentration $(0.5,1.0,2.0 \mathrm{wt} \% \mathrm{coating})$. The effectiveness of these coatings was assessed by the electrical conductivity (EC) and phosphorus release (PR) in a kinetic experiment. The kinetic study was carried out in a controlled environment $\left( \pm 25^{\circ} \mathrm{C}\right)$, following the release pattern of $P$ from $1.5 \mathrm{~g}$ of fertilizer in $50 \mathrm{~mL}$ of $\mathrm{H}_{2} \mathrm{O}$, with and without the coatings. The objective of this work was to study different lignin-based coatings and the phosphorus release behavior of the resulting fertilizer. EC showed to be an effective method of indirect analysis of $\mathrm{P}$ releasing from coated MAP. The BL coating presented better results than the CA in terms of controlling the release of $P$, and the higher the coating ratio $(1.0$ and $2.0 \%)$ the slower the release of $P$.
\end{abstract}

Keywords: Slow releasing, P-fertilizer, cellulose acetate, kraft black liquor.

Abbreviations: PUE_phosphorus use efficiency; $\mathrm{MAP}_{-}$monoammonium phosphate; $\mathrm{BL}$ _ Kraft black liquor; $\mathrm{CA}_{-}$cellulose acetate;

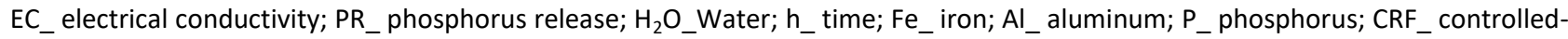
release fertilizers; $S_{R}$ _slow-release fertilizers; $E_{-} F_{-}$enhanced efficiency fertilizers; $C_{-}$carbon; $H_{-}$hydrogen; $N_{-}$nitrogen; $S_{-}$sulfur; $\mathrm{Na}$ _sodium; K_potassium.

\section{Introduction}

The need for more productive agricultural systems has required technological innovations that increase the efficiency of used inputs (Chien et al., 2009). The management of phosphate fertilizers is a key factor in crop production, which is especially the case in highly weathered tropical soil. Tropical soils have high levels of Fe-Al oxides clay and generally are very poor in $\mathrm{P}$, causing lower efficiencies of $P$ application (Roy et al., 2016). In these soils, the recovery of $P$ from fertilizers by annual crops vary from 5 to $25 \%$ in the year of application (Nyborg et al., 1995), but it can be as low as $0.61 \%$ in carrots (Santos et al., 2016). Most of it is because more than $90 \%$ of the applied $\mathrm{P}$ can be adsorbed in the first hour of contact with the soil (Novais et al., 2007). Thus, a proper management of $P$ fertilization is important to guarantee not only food production, but also to avoid environmental issues and to use wisely $P$, a rather scarce nutrient in the world (Ceulemans et al., 2011).

In that sense, it is well-known that a proper fertilization management is all about timing, placement, rate and source (4R Nutrient Stewardship). Among these, there is a fairly good understanding and management on timing, placement and rate of $P$ fertilizers application. However, in terms of sources, there is a lack of innovation and the need for new and more efficient products, which may improve the profitability of $\mathrm{P}$ fertilization, especially in areas with high $\mathrm{P}$ fixing soils and potentially leachable sandy soils.

Among these technologies, fertilizer coatings have been showing a good potential of increasing P efficiency especially by synchronizing plants demands and nutrient release from fertilizers (González et al., 2015), avoiding losses. Coating technologies are given different names in the literature such as controlled-release fertilizers (CRF), which consists of coating highly soluble granules with water-insoluble material. The slow-release fertilizers (SRF) are compounds that have low solubility in water by their own constitution. The enhanced efficiency fertilizers (EEF) are a combination of the so-called slow-release and controlled-release materials and are also referred as environmentally friendly fertilizers (EFF) (Chalk et al., 2015; González et al., 2015; Timilsena et al., 2015; Chen et al., 2018).

The coatings are synthetic or natural organic compounds. The synthetic coatings are mostly petroleum derivatives, more expensive and with unknown degradability in soil (Calabi-Floody et al., 2018). On the other hand, natural organic coatings are biodegradable and totally release the encapsulated nutrients (Schneider et al., 2016). Also, natural organic coatings can be cheaper, especially the organic polymers that are residues or by-products. Black liquor is an 
example of this type of material, which is rich in lignin, resulting from the manufacturing process of cellulose kraft pulp. Lignin is a copolymer of three different phenylpropane monomer units: sinapyl alcohol, coniferyl alcohol and pcoumaryl alcohol (Pandey and Kim, 2011).

Many natural polymeric materials have been mentioned in the literature as potential fertilizer coatings, including organic polymers such as Kraft pine lignin (García et al., 1996), cellulose acetate (Jarosiewicz and Tomaszewska, 2003), and sodium alginate (Liang et al., 2007). Lignin has also been investigated as a potential coating for nitrogen fertilizers (Mulder et al., 2011, González et al., 2015, Siponnen et al., 2016). On the other hand, little is known about the use of eucalypt black liquor from cellulose production in order to produce controlled release $P$ fertilizers. The production of cellulose from eucalypt is a blooming industry in Brazil. Thus, the use of its main residue (black liquor) is important to reduce environmental impacts of waste disposal and to generate added-value products.

The objective of this work was to develop an economically feasible and biodegradable layer as coating material for MAP fertilizer. For this purpose, from BL and CA of pulp and paper industries was selected as raw material, for the production of coatings to control $P$ release from MAP.

\section{Results}

The releases of $\mathrm{P}$ over time were adjusted as sigmoidal model. CA-coated MAP granules rapidly released $P$ over time (Figure 4A) compared to the BL-coated MAP (Figure 4B). As expected, uncoated MAP had the highest release rate of $P$ over time (Figure 4).

The results of the coefficients of the logistic equation regarding the release of $P$ were presented in Table 1 . The maximum release was $89.5 \%$ ("a" coefficient), which represents the saturation point and it is related to the maximum release of $P$ (granule dissolution in aqueous medium). Thus, the maximum release of $P$ at 98 hours followed the order: MAP > MAP-BL $1.0 \%>$ MAP-CA $2.0 \%>$ MAP-BL $2.0 \%>$ MAP-BL $0.5 \%>$ MAP-CA $0.5 \%>$ MAP-CA $1.0 \%$.

The "b" and "c" coefficients are related to the distribution of the data in the logistic equation and their results are used to calculate half of the release of $P$ over 98 hours. The values of $t \frac{1}{2}$ reflect the time each treatment took to release half of the $P$ concentration and, therefore the higher its value, the slow release it is.

Black liquor coated MAP (MAP-BL) treatments released $P$ slower than the other treatments. Although MAP-CA treatments had lower coefficient "a" (maximum release rate) compare to uncoated MAP, their " $b, c$ and $t 1 \frac{1}{2}$ " coefficients were similar, showing similar release rate of $P$ (Table 1).

The EC and released $P$ showed a positive correlation $(r=$ 0.927 and $p$-value $=0.001$ ) (Figure 5). This indicates that EC can be used for futures works to estimate the release of $P$ from MAP, in a simpler and faster way.

\section{Discussion}

Treatments with $B L$ had a better control on the release of $P$. Regarding the total amount release of $P$ in the solution, the treatment in which the MAP was coated with $1.0 \%$ of CA released less $P$ when compared to the others. It is noteworthy that the treatments with $2.0 \%$ and $0.5 \%$ coating presented higher release values when compared to $1.0 \%$, which may be related to the porosity and capillarity of the materials after the coating process, this is due to the better uniformity of the coating of the granules (Figure 2). The $0.5 \%$ coating was not sufficient to inhibit nutrient release through the pores, whereas the $2.0 \%$ treatment can form such a thick layer with small pores, that it acts as a capillary and contribute to the dislocation of $\mathrm{P}$ to exterior of the granule. For Han et al. (2009) coatings with films with lower water absorption were more effective in controlling the release of nutrients.

More specifically, $1.0 \%$ and $2.0 \%$ MAP-BL treatments took the longest to release half of the $P$ concentration, indicating a greater control over the release when compared to the treatments with CA coating. Probably, BL increased the hydrophobicity and decreased the water sensitivity of the coating. Therefore, the water uptake and as a result the release of $P$ decreased. Besides the hydrophobicity, the quality of the coating also has a great influence on the release of $P$.

Controlled release fertilizers are important among the technologies used to ensure the balance between the nutritional demands of the plant. Several materials can be used as coatings, which can be synthetic or organic origin. According to Shaviv (2005), non-biodegradable synthetic coating materials (polyolefin, polyurethane resins, and alkyd resins) contribute to environmental problems. Its use may lead to an undesirable accumulation of plastic waste up to $50 \mathrm{~kg} \mathrm{ha}^{-1}$ year $^{-1}$, once its degradation can take up to 10 years (Trenkel 2010).

It is noteworthy the importance of using materials of organic origin, such as $C$ and $B L$ of the pulp and paper industry, due to being biodegradable and in the case of $\mathrm{BL}$, it represents an industry residue that can return to the market as a co value-added product. Teixeira et al. (2016) observed that coated MAP granules from organic coating provided a gradual release of $P$ over time, and thus increased the availability of $P$ to plants, resulting in higher efficiency of $P$ use in maize plants.

The application of controlled release technology in fertilizers is based on the gradual release of nutrients to meet the plant demand and reduce the loss in the environment. However, the research needs to move forward to allow an understanding of the release pattern associated with this technology in order to properly regulate these products and provide information to the consumer.

The laboratory analyzes present as an advantage the precision during decision-making. On the other hand, it presents as a disadvantage its high cost, the waiting time to obtain results, besides presenting an environmental impact related to the use of chemical reagents and the water footprint necessary for the analysis and washing of glassworks. Reducing chemical analyzes or replacing them with indirect measures, may reduce waiting time, reduce cost and reduce associated environmental impact. Our study showed that EC can be used as an indirect measure of release of $P$, since the saline content in solution resulting from the dissolution of the fertilizer can be determined by direct reading in the apparatus. Messa et al. (2016) evaluated EC as a parameter of fertilizer release throughout time and verified a correlation between the EC and the concentration of $\mathrm{K}$ released in the soil. The $\mathrm{EC}$ is an effective 

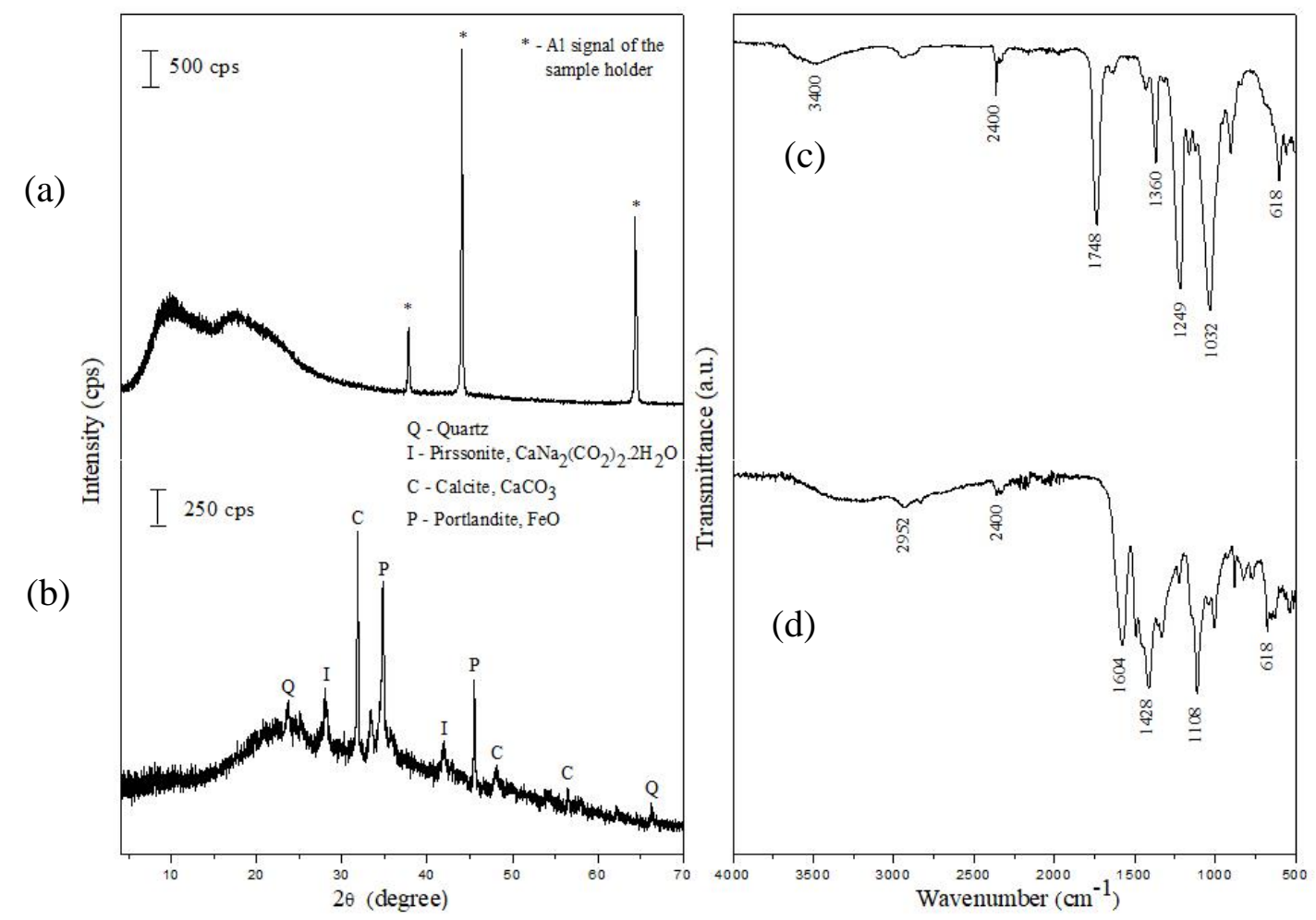

Fig 1. X-ray diffractograms and spectrum in the infrared region in the range of 4000 to 500 (FTIR/ATR) Cellulose Acetate (a, c) and Kraft Black Liquor (b, d).

Table 1. Coefficients of the logistic equation, determination, and time necessary to reach half of the cumulative maximum release in a period of 98 hours for the different coatings and the uncoated MAP.

\begin{tabular}{lccccc}
\hline \multirow{2}{*}{ Sources } & \multicolumn{5}{c}{ Release (\%) } \\
\cline { 2 - 6 } & $\mathrm{a}$ & $\mathrm{b}$ & $\mathrm{c}$ & $\mathrm{R}^{2}$ & $\mathrm{t} \mathrm{1} / 2(\mathrm{~h})$ \\
\hline MAP & 89.48 & -3.68 & 0.28 & 0.99 & 13.20 \\
T-1 $^{*}$ & 81.16 & -4.89 & 0.34 & 0.99 & 14.35 \\
T-2 & 74.67 & -4.52 & 0.29 & 0.98 & 15.48 \\
T-3 & 86.63 & -2.99 & 0.13 & 0.98 & 23.03 \\
T-4 & 84.65 & -2.49 & 0.09 & 0.98 & 26.46 \\
T-5 & 88.46 & -2.38 & 0.07 & 0.97 & 33.54 \\
T-6 & 85.86 & -2.70 & 0.07 & 0.98 & 35.62 \\
\hline T-1: MAP coating CA 0.5 \%, T-2: MAP coating CA 1.0 \%, T-3: MAP coating CA 2.0 \%, T-4: MAP coating BL 0.5 \%, T-5: MAP coating BL 1.0\%, T-6: MAP coating BL 2.0\%.
\end{tabular}

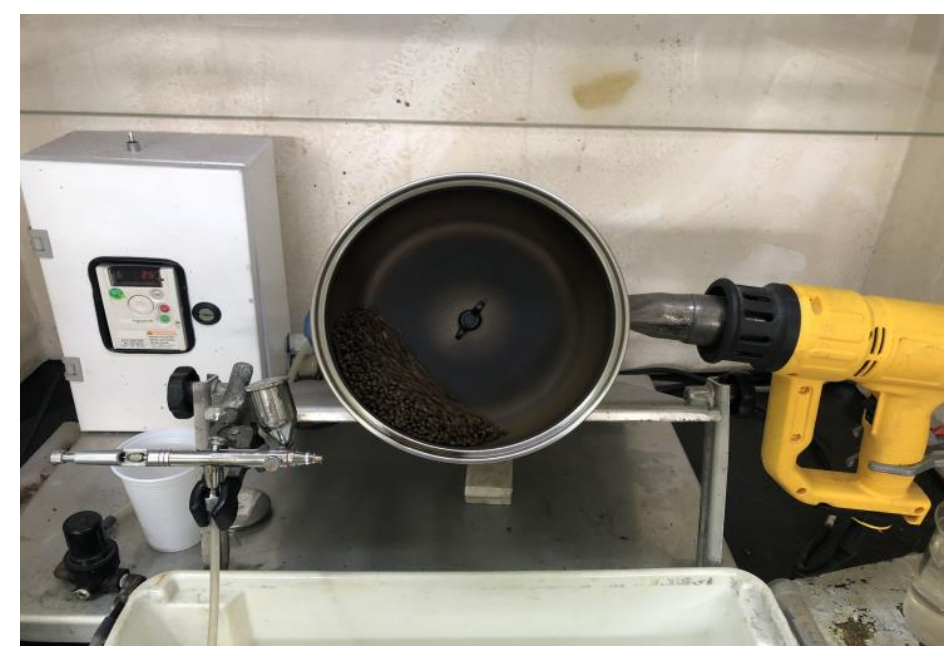

Fig 2. Granulator dish accompanied by heating gun and micro spray for fertilizer coating. 


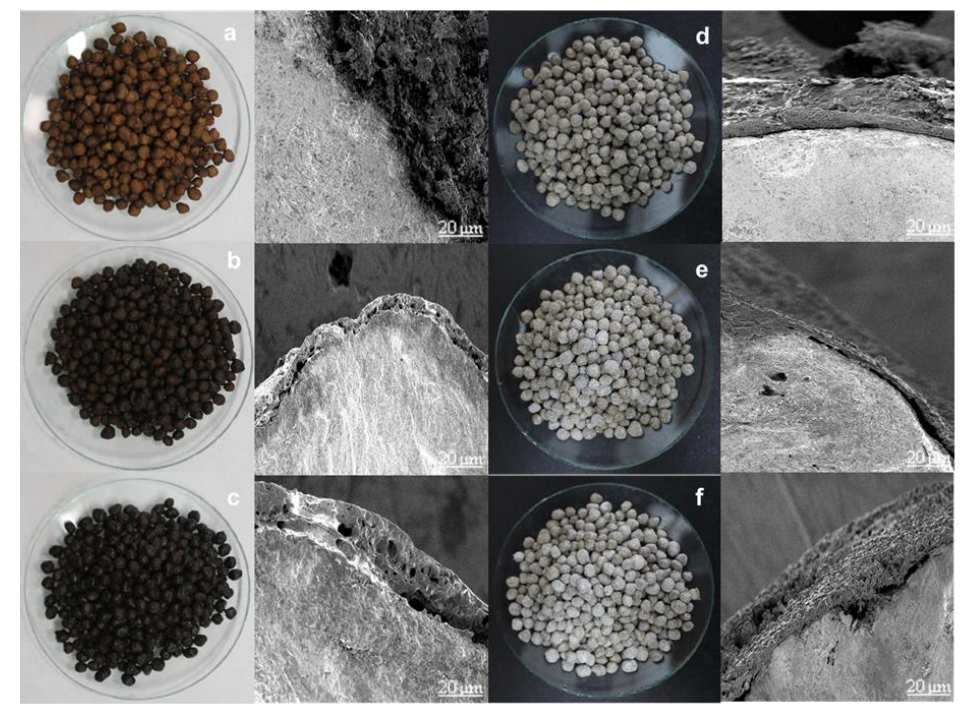

Fig 3. Different types of fertilizers/treatments used in this study. (a) Fertilizer coated with $0.5 \%$ Kraft black liquor; b) fertilizer coated with $1.0 \%$ Kraft black liquor; c) fertilizer coated with $2.0 \%$ Kraft black liquor; d) fertilizer coated with $0.5 \%$ cellulose acetate; e) fertilizer coated with $1.0 \%$ cellulose acetate; f) fertilizer coated with $2.0 \%$ cellulose acetate. Micrographs were acquired by a JEOL, JSM-6010LA with a spatial resolution of $20 \mu \mathrm{m}$ at $2 \mathrm{kV}$.

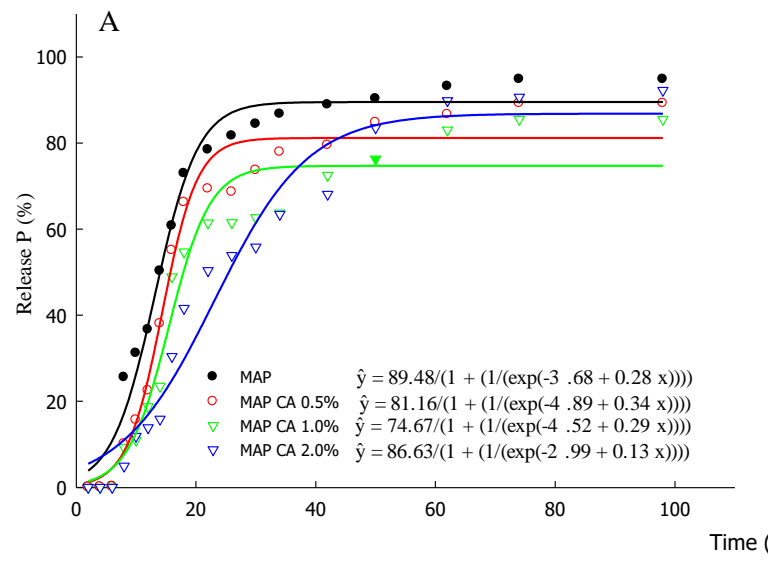

B

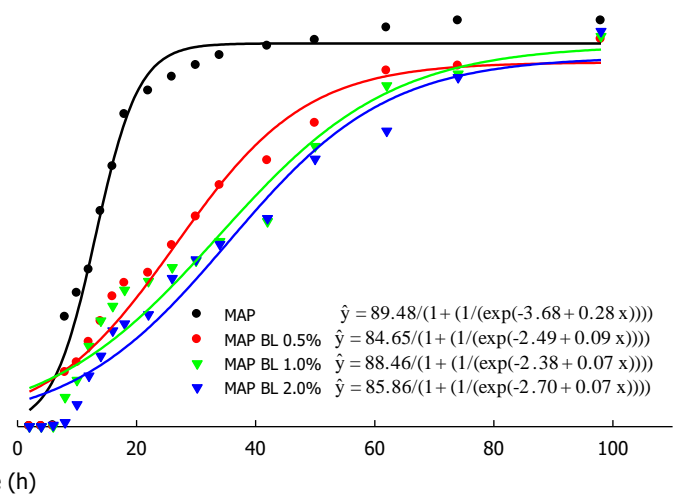

Fig 4. Release kinetics of $P$ at $25 \circ \mathrm{C}$ in water with conventional MAP $(\bullet)$, MAP-CA $0.5 \%(0)$, MAP-CA $1.0 \%(\nabla)$, MAP-CA $2.0 \%(\nabla)$, MAP-BL $0.5 \%(\bullet)$, MAP-BL $1.0 \%(\boldsymbol{\nabla})$, MAP-BL $2.0 \%(\boldsymbol{\nabla})$. Lines are fitted models to $y=a / 1+e^{-(b+c x)}$.

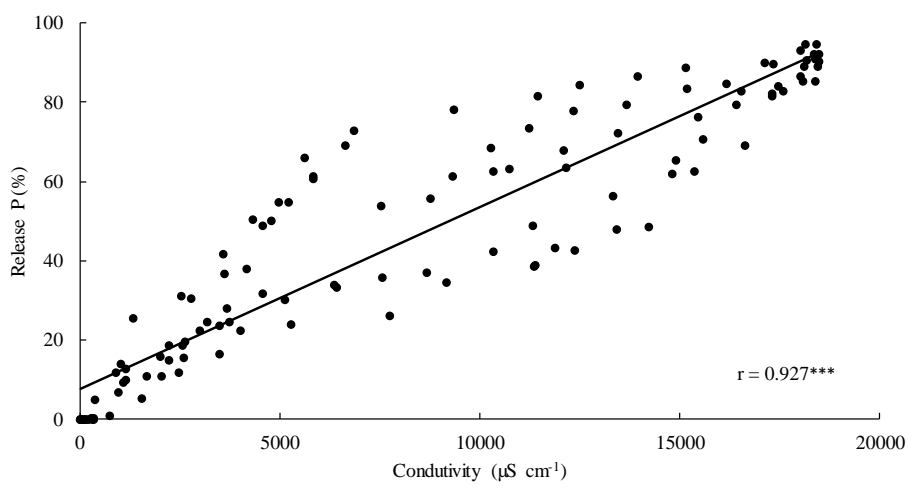

Fig 5. Pearson Correlation Analysis $(p$-value $=0.001)$ between electrical conductivity attributes $\left(\mu \mathrm{cm}^{-1}\right)$ and release $\mathrm{P}(\%)$, analyzed over time. 
parameter to follow the release of fertilizers, according to Souza et al. (2017).

These results reinforce the need for further studies on these coating technologies related to the constant and gradual $\mathrm{P}$, considering coating type (Guareschi et al., 2013.); coating quality and thickness (Rodrigues et al., 2013) the experimental environment, temperature and moisture. Any changes in these characteristics may reflect in contradictory or inconsistent results and interpretations.

\section{Materials and methods}

\section{Map and coating materials}

Fertilizer MAP was sieved to obtain granules between 2 and $3 \mathrm{~mm}$ and weight between 25 and $30 \mathrm{mg}$. Eucalypt Kraft Black Liquor was collected in Cenibra, a company located in the state of Minas Gerais, Brazil. The BL was oven dried at $105{ }^{\circ} \mathrm{C}$, for $24 \mathrm{~h}$ and grounded to $<100 \mu \mathrm{m}$. Then, the material was dissolved in water 1:10 $(\mathrm{w} / \mathrm{v})$, and afterwards was sprayed in MAP granules. The $\mathrm{BL}$ had the following elemental composition ( $\mathrm{g} / \mathrm{kg})$ : $\mathrm{C}-461 ; \mathrm{H}-44.3 ; \mathrm{N}-1.42 ; \mathrm{S}$ - 39.1; $\mathrm{Na}-158.9 ; \mathrm{K}-22.4$. Cellulose acetate was obtained from Sigma-Aldrich. In order to prepare the spray solution, 3 $\mathrm{g}$ of CA were dissolved in $250 \mathrm{~mL}$ of acetone, at room temperature for $24 \mathrm{~h}$. The coating materials were characterized by $\mathrm{X}$-ray diffraction and infrared spectroscopy (IR-ATR) and the results are shown in Figure 1.

\section{Coated map granules}

About $100 \mathrm{~g}$ of MAP granules were placed into a lab disk granulator inside of a fume hood. A spraying system consisting of a peristaltic pump with a micro spray was used to spray the coating materials solution on the moving granules in the coating pan. Tests were performed to obtain MAP granules with $0.5 ; 1.0$ and 2.0 wt \% of coating rate for $\mathrm{BL}$ and $\mathrm{CA}$. During the coating process, the disc was heated using a heat gun set between 100 and $120 \stackrel{\circ}{C}$ requiring no further drying (Figure 2). The coated granules were stored in an air and moisture free place at room temperature, around $25{ }^{\circ} \mathrm{C}$. Images of the granules after preparation and micrographs of transactional cuts of the granules are shown in figure 3.

\section{Nutrient release tests}

For the release of $\mathrm{P}$ from MAP granules coated with $\mathrm{BL}$ and CA, samples of $1.5 \mathrm{~g}$ of fertilizers with $0.5 ; 1$ and 2 wt \% of coating and $50 \mathrm{~mL}$ of deionized water were placed in glass recipients and incubated at $25 \stackrel{\circ}{\circ}$. An uncoated MAP was included as control. After 2, 4, 6, 8, 10, 12, 14, 16, 18, 22, 26, $30,34,42,50,62,74$, and $98 \mathrm{~h}, 250 \mu \mathrm{L}$ of solution were sampled to quantify $\mathrm{P}$ by colorimetry (Braga and Defelipo, 1974). The experiment was carried out using a completely randomized design with four replications. Simultaneously, another set of samples of $1.5 \mathrm{~g}$ of fertilizers were incubated the same way, with $50 \mathrm{~mL}$ of deionized water at $25 \stackrel{\circ}{\circ}$. At the same sampling time, EC was measured. Briefly, the EC probe was placed at nearly $1 \mathrm{~cm}$ from the bottom of recipient at a short distance from the granules. Afterward, $\mathrm{EC}$ and the release percentage of $\mathrm{P}$ were correlated.

\section{Data analysis}

The concentration of $P$ in solution was converted to the percentage of $P$ released from the MAP granules and then adjusted to the logistic equation $\left[Y=a / 1+e^{-(b+c x)}\right]$ (Castro et al., 2016; Ribeiro et al., 2016). The coefficient "a" is the saturation of the curve, associated with the maximum release of $\mathrm{P}$; " $\mathrm{b}$ " indicates the displacement of the curve horizontally and the greater this value, the greater the time to reach the saturation; and " $c$ " is related to the growth rate of the function, directly associated with the dissolution of $P$. These coefficients make it possible to estimate the time required to reach half of the release of $P\left(t \frac{1}{2}=-b / c\right)$. Pearson correlation coefficient for $\mathrm{P}$ concentration or release of $\mathrm{P} d$ from MAP and EC was carried out and a linear regression was fitted to describe their relation them. All statistical analysis was performed in $\mathrm{R}$ environment ( $\mathrm{R}$ Core Team, 2016).

\section{Conclusion}

This work demonstrates that the release of $\mathrm{P}$ in water was reduced with black liquor coated-MAP, especially with 2.0 wt $\%$ of coating rate. Cellulose acetate was less efficient than $B L$ in delay release of $P$ in water.

Electrical conductivity showed to be an effective method of indirect analysis of release of $\mathrm{P}$ from coated MAP.

\section{Acknowledgments}

We thank the Conselho Nacional de Desenvolvimento Científico e Tecnológico (CNPq) for research productivity scholarship for first author.

\section{References}

Braga JM, Defelipo BV (1974) Determinação espectrofotométrica de fósforo em extratos de solo e material vegetal. R Ceres. 21:73-85.

Calabi-Floody M, Medina J, Rumpel C, Condron LM, Hernandez M, Dumont M, Mora MDLL (2018) Smart Fertilizers as a Strategy for Sustainable Agriculture. Adv Agron. 147:119-157.

Castro JS, Calijuri ML, Assemany PP, Cecon PR, Assis IR, Ribeiro VJ (2017) Microalgae biofilm in soil: Greenhouse gas emissions, ammonia volatilization and plant growth. Sci. Total Environ. 574:1640-1648.

Ceulemans T, Merckx R, Hens M, Honnay O (2011) A traitbased analysis of the role of phosphorus vs. nitrogen enrichment in plant species loss across Northwest European grasslands. J Appl Ecol. 48:1155-1163.

Chalk PM, Craswell ET, Polidoro JC, Chen D (2015) Fate and efficiency of $15 \mathrm{~N}$-labelled slow- and controlled-release fertilizers. Nutr Cycl Agroecosyst. 102:167-178.

Chen S, Yang M, Ba C, Yu S, Jiang Y, Zou H, Zhang Y (2018) Preparation and characterization of slow-release fertilizer encapsulated by biochar-based waterborne copolymers. Sci Total Environ. 615:431-437. 
Chien S, Prochnow L, Cantarella H (2009) Recent developments of fertilizer production and use to improve nutrient efficiency and minimize environmental impacts. Adv Agron. 102:267-322.

García MC, Díez JA, Vallejo A, García L, Cartagena MC (1996) Use of Kraft Pine Lignin in Controlled-Release Fertilizer Formulations. Ind Eng Chem Res. 35:245-249.

González M, Cea M, Medina J, González A, Diez M, Cartes P, Monreal C, Navia R (2015) Evaluation of biodegradable polymers as encapsulating agents for the development of a urea controlled-release fertilizer using biochar as support material. Sci Total Environ. 505:446-453.

Guareschi RF, Gazolla PR, Perin A, Santini JMK (2011) Adubação antecipada na cultura da soja com superfosfato triplo e cloreto de potássio revestidos por polímeros. Ciênc Agrotec. 35:643-648.

Han X, Chen S, Hu X (2009) Controlled-release fertilizer encapsulated by starch/polyvinyl alcohol coating. Desalination. 240:21-26.

Jarosiewicz A, Tomaszewska M (2003) Controlled-release NPK fertilizer encapsulated by polymeric membranes. J Agric Food Chem. 51:413-417.

Liang R, Liu M, Wu L (2007) Controlled release NPK compound fertilizer with the function of water retention. React Funct Polym. 67:769-779.

Messaa LL, Froesb JD, Souzab CF, Faez R (2016) Híbridos de quitosana-argila para encapsulamento e liberação sustentada do fertilizante nitrato de potássio. Quím Nova. 39:1215-1220.

Mulder W, Gosselink R, Vingerhoeds M, Harmsen P, Eastham D (2011) Lignin based controlled release coatings. Ind Crop Prod. 34:915-920.

Novais RF, Smith TJ, Nunes FNP (2007) In: Novais R, Alvarez VVH, Barros NF, Fontes RL, Cantarutti RB, Neves JCL editors. Fertilidade do solo. 1a ed. Viçosa: SBCS. 472-547.

Nyborg M, Solberg E, Pauly D (1995) Coating of Phosphorus Fertilizers with Polymers Increases Crop Yield and Fertilizer Efficiency. Better Crops. 79:8-9.

Pandey MP, Kim CS (2011) Lignin depolymerization and conversion: a review of thermochemical methods. Chem Eng Technol. 34:29-41.

R Core Team (2016) R: A language and environment for statistical computing. $\mathrm{R}$ Foundation for Statistical Computing, Vienna, Austria. URL http://www.Rproject.org/.
Ribeiro VJ, Andrade FV, Souza CHE, Mendonça ES (2016). Volatilization of ammonia in stabilized slow-release nitrogen fertilizer under controlled conditions. AJCS. 6:793-798.

Rodrigues MAC, Buzetti S, Maestrelo PR, Lino ACM, Teixeira Filho MCM, Andreotti M, Garcia CMP (2013) Cloreto de potássio revestido em efeito residual no feijoeiro de inverno irrigado na região de cerrado. Semina: Ciênc Agrár. 34:1011-1022.

Roy ED, Richards PD, Martinelli LA, Coletta LD, Rafaela SLM, Vazquez FF, Willig E, Spera SA, Vanwey LK, Porder S (2016) The phosphorus cost of agricultural intensi fi cation in the tropics. Nat Plants. 2:2-7.

Santos LPD, Cunha MLP, Clemente JM, Oliveira TF, Aquino PM, Assunção NS (2016) Recovery efficiencies of nitrogen, phosphorus and potassium of the garlic crop. J Plant Nutr. 40:624-631.

Schneider TA, Deladino L, Zaritzky N (2016) Yerba mate (Ilex paraguariensis) waste and alginate as a matrix for the encapsulation of $\mathrm{N}$ fertilizer. ACS Sustain Chem Eng. 4:2449-2458

Shaviv A (2005) Controlled release fertilizers. IFA International Workshop on Enhanced-Efficiency Fertilizers, Frankfurt. International Fertilizer Industry Association Paris, France. IFA; 2005.

Sipponen MH, Rojas OJ, Pihlajaniemi V, Lintinen K, Österberg M (2016) Calcium chelation of lignin from pulping spent liquor for water-resistant slow-release urea fertilizer systems. ACS Sustain Chem Eng. 5:1054-1061.

Souza CF, Faez R, Bacalhau FB, Bacarin MF, Pereira TS (2017) In situ monitoring of a controlled release of fertilizers in lettuce crop. Eng. Agríc. 37:656-664.

Teixeira RDS, Silva IR, Sousa RN, Mattiello EM, Soares EMB (2016) Organic acid coated-slow-release phosphorus fertilizers improve $P$ availability and maize growth in a tropical soil. J Soil Sci Plant Nutr. 16:1097- 1112.

Timilsena YP, Adhikari R, Casey P, Muster T, Gill H, Adhikari B (2015) Enhanced efficiency fertilisers: a review of formulation and nutrient release patterns. J Sci Food Agric. 95:1131-1142.

Trenkel ME (2010) Slow- and controlled-release and stabilized fertilizers: an option for enhancing nutrient use efficiency in agriculture. Paris, Frace: International Fertilizer Industry Association. 